\title{
Reply to: 10-year outcomes after monitoring, surgery, or radiotherapy for localized prostate cancer. Hamdy et al. NEJM October 2016
}

\author{
$\operatorname{Max}_{\text {Peters }^{1}}{ }^{\mathbb{D}} \cdot{\text { Jochem R. N. van der Voort van } \mathrm{Zyp}^{1} \cdot \text { Helena M. Verkooijen }}^{2}$
}

Received: 11 November 2016 / Accepted: 27 January 2017 / Published online: 16 February 2017

(C) Springer-Verlag Berlin Heidelberg 2017

Dear Editor,

With great interest, we have read the results of the ProtecTtrial, comparing radical prostatectomy, radical radiotherapy, and active monitoring $[1,2]$. A number needed to treat (NNT) of 27 and 33 for prostatectomy and radiotherapy are stated, respectively, to prevent one patient developing metastases. The authors mention the effect of selection due to PSA-testing compared to the PIVOT and SPCG-4 trial and the advancements in treatment of nonprostatic disease. However, it might be the case that the NNT will drop with further follow-up due to this stage migration to lower risk disease. This lead-time bias has also been observed in subsequent reports of the ERSPC trial [3-5] (NNT/number needed to detect (NND) of 48 at 9 years, 37 at 11 years, and 27 at 13 years for one prostate-cancer death).

Furthermore, selection could indeed be improved with multi-parametric MRI, and treatment techniques are evolving, as stated. However, treatment-related side effects remain substantial [2]. The considerable probability of radical intervention in the active monitoring group might pave the way for tissue-preserving techniques if differences in effectiveness are so minor.
Compliance with ethical standards

Conflict of interest No potential conflict of interest relevant to this letter was reported.

\section{References}

1. Hamdy FC, Donovan JL, Lane JA et al (2016) 10-year outcomes after monitoring, surgery, or radiotherapy for localized prostate cancer. N Engl J Med 375:1415-1424

2. Donovan JL, Hamdy FC, Lane JA et al (2016) Patient-reported outcomes after monitoring, surgery, or radiotherapy for prostate cancer. N Engl J Med 375:1425-1437

3. Schröder FH, Hugosson J, Roobol MJ et al (2009) Screening and prostate-cancer mortality in a randomized European study. $\mathrm{N}$ Engl J Med 360:1320-1328

4. Schröder FH, Hugosson J, Roobol MJ et al (2012) Prostatecancer mortality at 11 years of follow-up. N Engl J Med 366:981-990

5. Schröder FH, Hugosson J, Roobol MJ et al (2014) Screening and prostate cancer mortality: results of the European Randomised Study of Screening for Prostate Cancer (ERSPC) at 13 years of follow-up. Lancet 384:2027-2035
Max Peters

m.peters-10@umcutrecht.nl

1 Department of Radiation Oncology, University Medical Center Utrecht, Utrecht, The Netherlands

2 Imaging Division, University Medical Center Utrecht, Utrecht, The Netherlands 